\title{
Serum Antioxidative Enzymes Levels and Oxidative Stress Products in Children and Adolescents with Type I Diabetes Mellitus
}

\author{
(D) Özlem Akgün, (1) Nilgün Selçuk Duru, (1) Murat Elevli \\ University of Health Sciences, İstanbul Haseki Training and Research Hospital, Clinic of Pediatrics, İstanbul, Turkey
}

\begin{abstract}
Aim: Type I diabetes mellitus (TIDM) is an oxidative stress condition in addition to being a chronic metabolic disease. In this study, our aim is to investigate the activity of antioxidative enzymes and the products of oxidative stress in children and adolescents with TIDM and compare the findings with those in healthy control subjects.

Materials and Methods: The study enrolled 41 children and adolescents with TIDM (mean age 11.4 \pm 3.3 years; 21 female, 20 male) and 25 healthy subjects (mean age 11.3 \pm 3.1 years; 8 female, 17 male) with a similar age and gender distribution. Serum samples were obtained to detect the antioxidative enzymes of paraoxonase (PON), arylesterase (ARE), oxidation degradation products of malondialdehyde (MDA) and also zinc which acts as an antioxidant.

Results: We found a significant decrease in PON activity and zinc levels in diabetics compared to the healthy controls ( $p=0.021 ; p<0.001$, respectively). Zinc was negatively correlated to hemoglobin A1c $(r=-0.317, p=0.049)$. MDA and ARE did not show a significant difference in the TIDM patients compared to the healthy subjects.

Conclusion: Zinc level and PON activity were lower in diabetic children and adolescents. Further studies with larger samples are required to confirm their roles in the following and prognosis of TIDM.

Keywords: Antioxidant, oxidative stress, paraoxonase, Type I diabetes mellitus, zinc
\end{abstract}

\section{Introduction}

Type I diabetes mellitus (TIDM) is the most common metabolic disorder resulting in the destruction of insulin producing pancreatic $\beta$-cells by lymphocytic infiltration (1). Genetic predisposition is important in the development of TIDM (2). In addition, some environmental factors such as viral infection, vaccines, low levels of vitamin $D$ and dietary factors during infancy may trigger the development of TIDM in those individuals with genetic susceptibility (2). Some metabolic and physiologic processes lead to reactive oxygen species (ROS) in the body. ROS are highly reactive molecules derived from the reduction of oxygen and can be harmful to some cell structures such as carbohydrates, nucleic acids, lipids and proteins (3). Their elimination is provided by the antioxidant defence system (4). Oxidative stress is the loss of balance between prooxidant and antioxidant systems (5). Oxidative stress may play a role in the pathogenesis of human diseases. Many studies have investigated the relationship between oxidative stress parameters and various

\section{Address for Correspondence}

Nilgün Selçuk Duru MD, University of Health Sciences, istanbul Haseki Training and Research Hospital, Clinic of Pediatrics, Istanbul, Turkey Phone: 905322564010 E-mail: nilgunduru@yahoo.com ORCID ID: orcid.org/0000-0001-9105-0529

The study originated from a thesis and has been previously presented at the $4^{\text {th }}$ Çocuk Dostları Kongresi, March-2016, istanbul/Turkey.

Received: 12.01.2018 Accepted: 11.04.2018

${ }^{\circledR}$ Copyright 2018 by Ege University Faculty of Medicine, Department of Pediatrics and Ege Children's Foundation The Journal of Pediatric Research, published by Galenos Publishing House. 
diseases such as some cancers, cardiovascular disease, Type II diabetes, cataracts and aging (5-9). Oxidative stress is believed to play a role both in the initial pathology of diabetes and in the development of vascular complications during the course of the disease (10-12). It can cause irreversible damage to the $\beta$-cells of the pancreatic islets (13). As a result, diabetic patients are susceptible to developing atherosclerotic cardiovascular diseases at early ages compared to healthy subjects (12). Many antioxidants are produced in the body to prevent the harmful effects of these oxidants (1). This study measured paraoxonase (PON) and arylesterase (ARE) activities as antioxidants, and the level of malondialdehyde (MDA), an end product of lipid peroxidation and the level of zinc which is a trace element acting as antioxidant in children with TIDM and also healthy control subjects. We aimed to compare them between groups and to investigate whether these parameters are associated with metabolic control, gender and diabetes duration.

\section{Materials and Methods}

\section{Study Groups}

The patient group consisted of 41 children and adolescents with TIDM (mean age $11.4 \pm 3.3$ years, 20 males and 21 females). The patients were diagnosed according to criteria provided by American Diabetes Association (14) and the presence of positive autoimmune antibodies. Exclusion criteria were as follows: other systemic diseases, abnormal renal/hepatic biochemical values or macrovascular complications. The control group consisted of 25 healthy subjects (mean age $11.3 \pm 3.1$ years; 8 female, 17 male). The study was approved by the University of Health Sciences, İstanbul Haseki Training and Research Hospital Local Ethics Committee (approval number: 48-11/10/2013). Written informed consent was obtained from each child included in the study or their parents before enrolling in the study. All patients had been treated with fast- and longacting insulin therapy from the onset of the disease. Data about the duration of illness and onset of the disease in those children with TIDM were obtained from the parents. Biochemical parameters such as glycosylated hemoglobin A1c ( $\mathrm{HbA1c}$ ) levels were determined in each child. The patients were also divided into subgroups according to their gender, glycaemic control (optimal and suboptimal glycaemic control: <9\%; poor glycaemic control: $\geq 9 \%$ ) (12) and duration of disease ( $\leq 1$ year; $>1$ year).

\section{Biochemical Analysis}

Venous blood samples were collected after overnight fasting and were centrifuged at 2.000 rpm for 20 minutes; serum samples were stored at $-70{ }^{\circ} \mathrm{C}$ until assayed. PON and ARE activities were measured by an enzyme-linked immunosorbent assay (ELISA) technique using an ELISA kit (Eastbiopharm, USA). The PON activity was determined using paraoxon as the substrate and measured by increases in the absorbance at $412 \mathrm{~nm}$ due to the formation of 4-nitrophenol. ARE activity was determined by measuring the rates of phenyl acetate and paraoxon hydrolysis at $548 \mathrm{~nm}$. MDA was analyzed by a spectrophotometric method. MDA was measured using thiobarbituric acid (TBA) reaction substance production in the following manner. $50 \mu \mathrm{L}$ of sample was added to $750 \mu \mathrm{L}$ of acetic acid (20\%), $100 \mu \mathrm{L}$ SDS (8.1\%), 750 $\mu \mathrm{L}$ TBA and $350 \mu \mathrm{L}$ distilled water. The mixture was heated at $100{ }^{\circ} \mathrm{C}$ for $45 \mathrm{~min}$. Then, $0.5 \mathrm{~mL}$ of distilled water and 2.5 $\mathrm{mL}$ of butanol-pyridine 15:1 were added to the mixture and incubated. Then, the absorbance at $532 \mathrm{~nm}$ was determined. Zinc was detected by a spectrophotometric method. HbA1c was analyzed using ion-exchange high performance liquid chromatography (Adams A1c, Arkray).

\section{Statistical Analysis}

SPSS (Statistical Package for the Social Science) 15.0 for Windows was used for the statistical analysis. Qualitative data are presented as counts and percentages. The association between qualitative variables was assessed using a chi-square test. Quantitative data are presented as mean \pm standard deviation for normally distributed data or otherwise as median and interquartile range. Student's t-test for independent samples was used to check for differences between two independent groups of normally distributed data and also by the Mann-Whitney $U$ test. Spearman correlation coefficient was used to assess the relations between quantitative variables not following a normal distribution. $\mathrm{P}<0.05$ was considered as statistically significant.

\section{Results}

The study group comprised of 41 children and adolescents that were diagnosed with TIDM. Some markers related to oxidative stress were compared with a known control group of 25 healthy children and adolescents.

The mean age in the group was $11.4 \pm 3.3$ years (range 3.5-18 years) and was similar to the control group $11.3 \pm 3.1$ years (range 6-16 years) $(p=0.912)$. There were 21 female $/ 20$ male $(51.2 \%$ female $/ 48.8 \%$ male) in the TIDM group and 8 female/17 male (32.0\% female/68.0\% male) in the control group. The gender distribution was similar in both groups $(p=0.127)$. The main characteristics of the groups in the study are summarized in Table I. The average time from diagnosis of TIDM to participating in this study was 34.0 \pm 49.2 months (range 0-192 months). The average HbA1c value in the patients with TIDM was $11.0 \pm 2.5 \%$ (range $6.8-15.3 \%$ ). While 28 of the children with TIDM had poor metabolic control, 13 patients had good metabolic control (Table I).

Regarding PON activities and zinc levels, we found statistically significant lower values for the diabetics compared to the controls ( $p<0.001, p=0.021$, respectively). Also, ARE activity was lower in the diabetics vs. the controls, 
Table I. Demographic features and biochemical data of the diabetic and control groups

\begin{tabular}{|l|l|l|l|}
\hline Parameters & Type I diabetics & Control group & $\mathbf{p}$ value \\
\hline Age (years) & $11.4 \pm 3.3(3.5-18)$ & $11.3 \pm 3.1(6-16)$ & 0.912 \\
\hline Gender (females, \%) & $21(51.2)$ & $8(32.0)$ & 0.127 \\
\hline Duration of diabetes (month) & $34.0 \pm 49.2(0-192)$ & - & - \\
\hline Long-acting insulin (U/day) & $15.1 \pm 8.7(4-36)$ & - & - \\
\hline Fast-acting insulin (U/day) & $20.2 \pm 11.7(6-45)$ & - & - \\
\hline HbA1c (\%) & $11.0 \pm 2.5(6.8-15)$ & - & - \\
\hline Zinc (mcg/dL) & $103.9 \pm 51.9(0.98-278)$ & $163.8 \pm 40.6(88-244.6)$ & $<0.001^{* *}$ \\
\hline Malondialdehyde (nmol/L) & $108.1 \pm 166.5(18-502)$ & $123.7 \pm 181.3(18-502)$ & 0.402 \\
\hline Paraoxonase (ng/mL) & $10.60 \pm 12.05(3.6-37.65)$ & $13.82 \pm 13.87(3.3-37.65)$ & $\mathbf{0 . 0 2 1 ^ { * }}$ \\
\hline Arylesterase (ng/mL) & $0.19 \pm 0.32(0.06-1.18)$ & $0.28 \pm 0.47(0.06-1.98)$ & 0.177 \\
\hline
\end{tabular}

${ }^{*} \mathrm{p}<0.05,{ }^{* *} \mathrm{p}<0.001$, Data are mean \pm standard deviation, HbA1c: Hemoglobin A1c

Table II. Biochemical parameters comparison between diabetic children Type I diabetes mellitus and controls according to gender

\begin{tabular}{|c|c|c|c|c|c|}
\hline & & Type I diabetics & & Control group & \\
\hline & & Mean \pm SD & $p$ value & Mean \pm SD & $p$ value \\
\hline \multirow[t]{2}{*}{ Zinc (mcg/dL) } & Female & $88.73 \pm 32.33$ & \multirow[t]{2}{*}{0.095} & $158.28 \pm 41.40$ & \multirow[t]{2}{*}{0.651} \\
\hline & Male & $119.90 \pm 63.62$ & & $166.40 \pm 41.28$ & \\
\hline \multirow[t]{2}{*}{ Malondialdehyde (nmol/L) } & Female & $101.11 \pm 171.32$ & \multirow[t]{2}{*}{0.151} & $159.93 \pm 213.49$ & \multirow[t]{2}{*}{0.380} \\
\hline & Male & $115.43 \pm 165.53$ & & $106.69 \pm 168.63$ & \\
\hline \multirow[t]{2}{*}{ Paroxonase (ng/mL) } & Female & $10.55 \pm 12.28$ & \multirow[t]{2}{*}{0.314} & $19.11 \pm 16.27$ & \multirow[t]{2}{*}{0.539} \\
\hline & Male & $10.65 \pm 12.12$ & & $11.33 \pm 12.34$ & \\
\hline \multirow[t]{2}{*}{ Arylesterase (ng/mL) } & Female & $0.22 \pm 0.37$ & \multirow[t]{2}{*}{0.449} & $0.39 \pm 0.67$ & \multirow[t]{2}{*}{0.793} \\
\hline & Male & $0.17 \pm 0.25$ & & $0.22 \pm 0.36$ & \\
\hline
\end{tabular}

Data are mean $\pm \mathrm{SD}, \mathrm{SD}$ : Standard deviation

but not statistically significant ( $p=0.177$ ). MDA levels of the diabetic patients were not statistically significant different from those of the controls ( $p=0.402$ ) (Table I). We compared the parameters measured in the diabetic patients and the control group according to gender (Table II). We did not observe any significant difference between female and male children for PON, ARE activities, MDA and zinc levels (Table II).

We stratified the patients according to disease duration above and below one year. We did not observe any significant difference between children having a diabetes duration above one year and those below one year for PON, ARE, MDA and zinc (Table III). We compared the parameters measured in the diabetic group according to metabolic control. There was not a statically significant difference between children with poor and good metabolic control for PON, ARE, MDA and zinc (Table IV). A negative correlation was observed between zinc and HbA1c in children with TIDM (Rho=-0.317, $\mathrm{p}=0.049)$.

\begin{tabular}{|c|c|c|c|}
\hline & \multicolumn{2}{|c|}{ Duration of diabetes } & \\
\hline & $\leq 1$ year & $>1$ year & \\
\hline & Mean \pm SD & Mean \pm SD & $p$ value \\
\hline Zinc (mcg/dL) & $107.45 \pm 51.03$ & $101.37 \pm 55.03$ & 0.655 \\
\hline $\begin{array}{l}\text { Malondialdehyde } \\
\text { (nmol/L) }\end{array}$ & $95.64 \pm 161.72$ & $124.71 \pm 177.30$ & 0.613 \\
\hline Paraoxonase $(\mathrm{ng} / \mathrm{mL})$ & $9.83 \pm 12.23$ & $11.54 \pm 12.40$ & 0.714 \\
\hline Arylesterase (ng/mL) & $0.17 \pm 0.29$ & $0.22 \pm 0.35$ & 0.924 \\
\hline
\end{tabular}

Data are mean $\pm S D$, SD: Standard deviation 
Table IV. Biochemical parameters in Type I diabetes mellitus patients according to hemoglobin A1c levels $<9 \%$ and $\geq 9 \%$

\begin{tabular}{|l|l|l|l|}
\hline & HbA1c $<\mathbf{9 \%}$ & HbA1c $\geq \mathbf{9 \%}$ & \\
\hline & Mean $\mathbf{9}$ SD & Mean $\mathbf{~ S D ~}$ & $\mathbf{p}$ value \\
\hline Zinc $(\mathrm{mcg} / \mathrm{dL})$ & $89.24 \pm 38.51$ & $111.11 \pm 57.20$ & 0.206 \\
\hline $\begin{array}{l}\text { Malondialdehyde } \\
\text { (nmol/L) }\end{array}$ & $101.20 \pm 157.64$ & $116.82 \pm 176.84$ & 0.813 \\
\hline $\begin{array}{l}\text { Paraoxonase } \\
\text { (ng/mL) }\end{array}$ & $9.16 \pm 11.11$ & $11.54 \pm 12.86$ & 0.309 \\
\hline Arylesterase $(\mathrm{ng} / \mathrm{mL})$ & $0.08 \pm 0.04$ & $0.25 \pm 0.37$ & 0.472 \\
\hline
\end{tabular}

Data are mean \pm SD, SD: Standard deviation, HbA1c: Hemoglobin A1c

Table V. Correlations of zinc, malondialdehyde, paraoxonase and arylesterase with age, duration of diabetes and hemoglobin A1c in children with Type I diabetes mellitus

\begin{tabular}{|l|l|l|l|l|l|}
\hline \multicolumn{2}{|l|}{} & Age & $\begin{array}{l}\text { Duration } \\
\text { of TIDM }\end{array}$ & HbA1c & Zinc \\
\hline \multirow{2}{*}{ Zinc (mcg/dL) } & rho & -0.193 & -0.087 & $-\mathbf{0 . 3 1 7 *}$ & - \\
\cline { 2 - 6 } & $p$ & $\mathbf{0 . 1 2 6}$ & 0.591 & $\mathbf{0 . 0 4 9 *}$ & - \\
\hline $\begin{array}{l}\text { Malondialdehyde } \\
\text { (nmol/L) }\end{array}$ & rho & $\mathbf{0 . 2 9 9 ^ { * }}$ & 0.211 & 0.051 & -0.108 \\
\cline { 2 - 6 } & $p$ & $0.016^{*}$ & 0.192 & 0.758 & 0.390 \\
\hline $\begin{array}{l}\text { Paraoxonase } \\
\text { (ng/mL) }\end{array}$ & rho & 0.201 & -0.003 & 0.057 & 0.231 \\
\cline { 2 - 6 } & $p$ & 0.112 & 0.987 & 0.732 & 0.062 \\
\hline $\begin{array}{l}\text { Arylesterase } \\
\text { (ng/mL) }\end{array}$ & rho & $\mathbf{0 . 3 3 5 ^ { * }}$ & 0.264 & 0.185 & 0.170 \\
\cline { 2 - 6 } & $p$ & $\mathbf{0 . 0 0 7 *}$ & 0.100 & 0.259 & 0.172 \\
\hline
\end{tabular}

${ }^{*} \mathrm{p}<0.05, \mathrm{HbA1c}$ : Hemoglobin A1c, TIDM: Type I diabetes mellitus

Age was positively correlated with ARE and MDA in the diabetic subjects ( $R h o=0.335, p=0.007 ;$ rho $=0.299, p=0.016$ respectively) (Table V).

\section{Discussion}

Free oxygen radicals interact with cellular components such as proteins, lipids and nucleic acids and start lipid peroxidation (15). In an organism, production of free oxygen radicals and antioxidant defence mechanisms are in balance, and as long as this oxidative balance is kept, oxidative stress cannot damage the organism $(1,15)$. Diabetes mellitus is associated with an endogenous inflammatory process and oxidative stress $(1,10,13,16,17)$. The destruction of insulin producing $\beta$ cells in TIDM patients elevates the plasma sugar level (18). It is a thought that high glucose levels trigger oxidative stress and increase ROS in diabetics (18). In addition, the balance between oxidative and antioxidant processes is sensitive to the plasma glucose level (19). Therefore, an increase in ROS is generally accompanied by a decrease in antioxidant defence in TIDM patients $(18,19)$. Prolonged oxidative stress may be associated with chronic complications of diabetes. As a result, diabetic patients are predisposed to atherosclerosis beginning at an early age (20). Most of the studies addressing these mechanisms were performed with diabetic adult patients (17,20-22). Therefore, the present study aimed to evaluate the biochemical markers of oxidative stress in children with TIDM. The end product of lipid peroxidation, MDA is an important marker of oxidative stress (23). High MDA levels were showed in diabetics (2124). In some studies, statistically significantly higher levels were reported for patients with poor metabolic control than in patients with suboptimal and optimal metabolic control $(17,21,23,25)$. These studies suggested that high glucose levels lead to lipid peroxidation and consequently to increased MDA (25). Erciyas et al. (23) proposed that the elevated MDA levels in children with TIDM with poor metabolic control may lead to vascular complications. Also, they recommended that MDA should be added to the routine laboratory evaluations in the follow-up of these patients (23). In contrast to these studies, Reis et al. (20) reported low MDA levels in patients with TIDM. In our study, MDA was similar between children with TIDM and the healthy controls. Also, MDA was not different between the groups in terms of disease duration, glycaemic control and gender. The reason for the different results in the studies is probably that many different enzymes and proteins play a role in oxidative stress. Enzymes with important functions in the fight against free radicals are known as antioxidants. PON and ARE have antioxidant and antiatherogenic effects. They are encoded by the same gene (26). Although PON shows polymorphic change, ARE does not show a genetic polymorphic change (26). There are studies indicating that PON polymorphism is a genetic predisposition to the complications of diabetes $(27,28)$. Also, although the two enzymes have different natural substrates, the PON has the ability to hydrolyse phenylacetate, the natural substrate of ARE. PON prevents lipid oxidation which plays an important role in the development of micro- and macrovascular disease $(12,27)$. Studies showed that PON activity was statistically significantly lower in patients with Type I diabetes compared to control groups $(12,28,29)$. Craciun et al. (12) did not observe a correlation between PON activity and HbA1c in children with TIDM. In our study as in that of Craciun et al., (12) PON activity in the patient group was statistically significantly lower than in the controls but its correlation with HbA1c was not observed. Although ARE activity was lower than the control group; this difference 
was not statistically significant. This result can be attributed to the fact that ARE activity is weaker than PON activity. However, the reason for decreased PON activity in patients with TIDM observed in our study as with studies of other investigators is still not fully understood (29). A possible explanation could be a modification of the enzyme's active centre affected by the glycation process. Even though we did not observe a negative correlation between the HbA1c value and PON activity, we speculated that lower PON activity in Type I diabetic patients could be the result of chronic hyperglycemia. Răchişan et al. (30) showed lower activities of PON and ARE in girls with TIDM than boys with ARE. There was no difference in PON and ARE activities in terms of gender in our study. In a study using a diabetic rat model, MDA and blood glucose were reduced in rats with TIDM treated with curcumin but superoxide dismutase and insulin increased (13). Curcumin is a kind of spice extensively used in Asian countries. It has antioxidant and anti-inflammatory effects (13). The antioxidant treatment is thought to improve beta-cell dysfunction, but the results are uncertain (31). Zinc is an essential element for the storage, secretion and action of insulin (31). In addition, it is a key co-factor of many antioxidant enzymes and also helps decrease the effects of inflammatory substances and oxidative stress (31). Zinc stimulates the synthesis of metallothionein, which cleanses hydroxyl radicals (31). Zinc transportation to insulin vesicles is facilitated by ZnT8 which is a transmembranic protein $(31,32)$. Antibodies against ZnT8 are produced in patients with TIDM (33). A study from Sweden showed that low zinc in drinking water is associated with the risk of developing Type I diabetes during childhood (33). Lin et al. (34) did not observed a significant difference in zinc levels between diabetics and controls. As opposed to this study, serum zinc levels in our study were significantly lower in the diabetic patient group than in the control group. The reason for decreased zinc levels in our study is not clear. But a negative correlation with $\mathrm{HbA1c}$ was observed in this study. This result suggests that the decrease in zinc may be due to hyperglycemia. The small sample size was the main limitation of this study.

\section{Conclusion}

PON, ARE activities and zinc levels were lower in children and adolescents with TIDM, but the decrease in the ARE activity was not statistically significant. In addition, a negative correlation was observed between zinc and HbA1c. Our results showed that the antioxidant defence systems decreased in children with TIDM. We conclude that antioxidant enzymes should be at normal levels to prevent or delay the complications of Type I diabetes in children, so we suggest that children with TIDM should adopt more physical activity, a healthier diet and less stressful lifestyle.

\section{Acknowledgements}

The authors thank for the financial support provided by University of Health Sciences Haseki Training and Research Hospital, İstanbul, Turkey, Project No: 15

\section{Ethics}

Ethics Committee Approval: The study was approved by the University of Health Sciences Haseki Training and Research Hospital Local Ethics Committee (approval number: 48-11/10/2013).

Informed Consent: Consent form was filled out by all participants.

Peer-review: Externally peer-reviewed.

\section{Authorship Contributions}

Surgical and Medical Practices: Ö.A., N.S.D., Concept: N.S.D., Design: N.S.D., Data Collection or Processing: Ö.A., N.S.D., Analysis or Interpretation: Ö.A., N.S.D., M.E., Literature Search: Ö.A., N.S.D., Writing: N.S.D.

Conflict of Interest: No conflict of interest was declared by the authors.

Financial Disclosure: The authors declared that this study received no financial support.

\section{References}

1. Castro-Correia C, Maia ML, Norberto S, et al. Can Antioxidative Status Be Involved in Type 1 Diabetes? J Clin Med Res 2017;9:9981001.

2. Tomita T. Apoptosis of pancreatic $\beta$-cells in Type 1 diabetes. Bosn I Basic Med Sci 2017;17:183-93.

3. Beckhauser TF, Francis-Oliveira J, De Pasquale R. Reactive Oxygen Species: Physiological and Physiopathological Effects on Synaptic Plasticity. J Exp Neurosci 2016:10(Suppl 1);23-48.

4. Apostolova N, Victor VM. Molecular strategies for targeting antioxidants to mitochondria: therapeutic implications. Antioxid Redox Signal 2015;22:686-729.

5. Samoylenko A, Hossain JA, Mennerich D, Kellokumpu S, Hiltunen JK, Kietzmann T. Nutritional countermeasures targeting reactive oxygen species in cancer: from mechanisms to biomarkers and clinical evidence. Antioxid Redox Signal 2013;19:2157-96.

6. Chang $D$, Zhang $X$, Rong $S$, et al. Serum antioxidative enzymes levels and oxidative stress products in age-related cataract patients. Oxid Med Cell Longev 2013;2013:587826.

7. Skibska B, Goraca A. The protective effect of lipoic acid on selected cardiovascular diseases caused by age-related oxidative stress. Oxid Med Cell Longev 2015;2015:313021.

8. Coudriet GM, Delmastro-Greenwood MM, Previte DM, et al. Treatment with a Catalytic Superoxide Dismutase (SOD) Mimetic Improves Liver Steatosis, Insulin Sensitivity, and Inflammation in Obesity-Induced Type 2 Diabetes. Antioxidants (Basel) 2017;6:E85.

9. Kubo E, Chhunchha B, Singh P, Sasaki H. Singh DP. Sulforaphane reactivates cellular antioxidant defense by inducing Nrf2/ ARE/Prdx6 activity during aging and oxidative stress. Sci Rep 2017;7:14130.

10. Barseem N, Elsamalehy M. Gene Polymorphisms of Glutathione S-Transferase T1/M1 in Egyptian Children and Adolescents with 
Type 1Diabetes Mellitus. J Clin Res Pediatr Endocrinol 2017;9:13843.

11. Aral CA, Nalbantoğlu Ö, Nur BG, Altunsoy M, Aral K. Metabolic control and periodontal treatment decreases elevated oxidative stress in the early phases of type 1 diabetes onset. Arch Oral Biol. 2017;82:115-20.

12. Craciun EC, Leucuta DC, Rusu RL, David BA, Cret V, Dronca E. Paraoxonase-1 activities in children and adolescents with type 1 diabetes mellitus. Acta Biochim Pol 2016;63:511-5.

13. Xie Z, Wu B, Shen G, Li X, Wu Q. Curcumin alleviates liver oxidative stress in type 1 diabetic rats. Mol Med Rep 2018;17:103-8.

14. American Diabetes Association. Diagnosis and classification of diabetes mellitus. Diabetes Care 2012;35(Suppl 1):64-71.

15. Altan N, Dinçel A, Koca C. Diabetes mellitus and oxidative stress. Turk J Biochem 2006;31:51-6.

16. Kaneto $H$, Katakami N, Kawamori $D$, et al. Involvement of oxidative stress in the pathogenesis of diabetes. Antioxid Redox Signal 2007;9:355-66.

17. Lin CC, Huang $\mathrm{HH}, \mathrm{Hu} C W$, et al. Trace elements, oxidative stress and glycemic control in young people with type 1 diabetes mellitus. I Trace Elem Med Biol 2014;28:18-22.

18. Fatima N, Faisal SM, Zubair S, et al. Role of Pro-Inflammatory Cytokines and Biochemical Markers in the Pathogenesis of Type 1 Diabetes: Correlation with Age and Glycemic Condition in Diabetic Human Subjects. PLoS One 2016;11:e0161548.

19. Menon $V_{1}$ Ram $M$, Dorn /, et al. Oxidative stress and glucose levels in a population-based sample. Diabet Med 2004;21:1346-52.

20. Reis IS, Veloso CA, Volpe CM, et al. Soluble RAGE and malondialdehyde in type 1 diabetes patients without chronic complications during the course of the disease. Diab Vasc Dis Res 2012;9:309-14.

21. Matteucci E, Giampietro O. Oxidative stress in families of type 1 diabetic patients. Diabetes Care 2000;23:1182-6.

22. Koca C, Altan N, Dincel AS, Kosova F. Oxidative stress and serum leptin levels in patients with type 1 and 2 diabetes mellitus. Turk J Biochem 2008;6:99-107.
23. Erciyas F, Taneli F, Arslan B, Uslu Y. Glycemic control, oxidative stress, and lipid profile in children with type 1 diabetes mellitus. Arch Med Res 2004;35:134-40.

24. Abou-Seif MA, Youssef AA. Evaluation of some biochemical changes in diabetic patients. Clin Chim Acta 2004;346:161-70.

25. Mishra N, Singh N. Blood viscosity, lipid profile, and lipid peroxidation in type-1 diabetic patients with good and poor glycemic control. N Am J Med Sci 2013;5:562-6.

26. Kurban S, Akpınar Z, Mehmetoğlu i. Investigation of serum paraoxonase and arylesterase activities and oxidative stress in patients with multiple sclerosis. Genel Tıp Derg 2010;20:13-7.

27. Hofer SE, Bennetts B, Chan AK, et al. Association between PON 1 polymorphisms, PON activity and diabetes complications. J Diabetes Complications 2006;20:322-8.

28. Fekih $\mathrm{O}$, Triki S, Rejeb), et al. Paraoxonase 1 polymorphisms (L55M and Q192R) as a genetic marker of diabetic nephropathy in youth with type 1 diabetes. Endokrynol Pol 2017;68:35-41.

29. Wegner M, Pioruńska-Stolzmann M, Araszkiewicz A, ZozulińskaZiótkiewicz D, Wierusz-Wysocka B. Evaluation of paraoxonase 1 arylesterase activity and lipid peroxide levels in patients with type 1 diabetes. Pol Arch Med Wewn 2011;121:448-54.

30. Răchişan AL, David BA, Căinap S, Miu N, Andreica M, Samaşca G. Immunological manifestations in type I diabetic children. Roum Arch Microbiol Immunol 2012;71:95-9.

31. Gerber PA, Rutter GA. The Role of Oxidative Stress and Hypoxia in Pancreatic Beta-Cell Dysfunction in Diabetes Mellitus. Antioxid Redox Signal 2017;26:501-18.

32. Elmaoğulları S, Uçaktürk SA, Elbeg Ş, et al. Prevalence of ZnT8 Antibody in Turkish Children and Adolescents with New Onset Type 1 Diabetes. I Clin Res Pediatr Endocrinol 2018;10:108-12.

33. Samuelsson $U$, Oikarinen $\mathrm{S}$, Hyöty $\mathrm{H}$, Ludvigsson J. Low zinc in drinking water is associated with the risk of type 1 diabetes in children. Pediatr Diabetes 2011;12:156-64.

34. Lin CC, Tsweng G), Lee CF, Chen BH, Huang YL. Magnesium, zinc, and chromium levels in children, adolescents, and young adults with type 1 diabetes. Clin Nutr 2016;35:880-4. 